\title{
A flavonol synthase gene GtFLS defines anther-specific flavonol accumulation in gentian
}

\author{
Soichi Kimura ${ }^{\dagger}$, Takashi Nakatsuka ${ }^{\dagger}$, Eri Yamada, Misa Saito, Masahiro Nishihara* \\ Iwate Biotechnology Research Center, Kitakami, Iwate 024-0003, Japan \\ *E-mail: mnishiha@ibrc.or.jp TEL: +81-197-68-2911 FAX: +81-197-68-3881
}

Received September 24, 2010; accepted November 9, 2010 (Edited by N. Ohtsubo)

\begin{abstract}
Flavonoids are important for male gametophyte development. Here we report on the flavonoid components and their biosynthetic regulation in gentian anthers. Among flavonoids, flavonols, including kaempferol, quercetin and isorhamnetin derivatives, accumulated abundantly in gentian anthers. However, flavones and anthocyanins, which are the main flavonoids accumulating in petals, were not detected. Northern blot analysis of nine flavonoid biosynthetic genes showed that the 'early' flavonoid biosynthetic genes were expressed in both anthers and petals, and that flavonol synthase $(F L S)$ transcripts were restricted to anthers. In contrast, flavone synthase II (FNSII) and 'late' flavonoid biosynthetic genes were expressed specifically in gentian petals. To confirm anther-specific expression of $F L S$, the $5^{\prime}$-upstream region of $F L S$ (GtFLSpro) was cloned by inverse PCR and fused to the uidA (GUS) reporter gene. Tobacco, Arabidopsis and gentian plants, transformed with the GtFLSproGUS construct, exhibited anther-specific GUS expression. Expression was observed in the tapetum and in pollen at late stages of anther development in transgenic plants. These results revealed that flavonol accumulation in gentian anthers was regulated by the spatial expression of GtFLS. Our results also suggest that antherspecific regulation of FLS is conserved among higher plants and the GtFLS promoter is useful for induction of specific gene expression in anthers.
\end{abstract}

Key words: Anther, flavonol synthase, gentian, promoter, transgenic plants.

Flavonoids are secondary metabolites synthesized via the phenylpropanoid pathway, and are responsible for a wide variety of biological functions in higher plants. For example, they are involved in pigmentation of flowers and fruits, defense against phytopathogens, protection against ultraviolet light, and induction of nodulation in legumes. They have also been implicated in regulation of auxin transport and resistance to insect pests (reviewed by Harborn and Williams 2000).

In most plant species, flavonoid compounds are present in pollen grains. The pollen grain wall is composed of an inner layer (intine) and an outer layer (exine). The exine plays an important role in protecting pollen from environmental stresses and microbial attack, and in cell-cell recognition during pollination. The exine is frequently decorated with complex patterns of spines and ridges. The exine wall is also composed primarily of sporopollenin, which is extremely resistant to decay and is formed from a series of related polymers derived from long-chain fatty acids and modest amounts of oxygenated aromatic rings and phenylpropanoids, including flavonoids (Piffanelli et al. 1998). The principal site of flavonoid synthesis in the anther is the tapetum, from which the pigments are transported into the locule and incorporated in the outer surface of the pollen grain (Wiermann and Gubatz 1992). At later stages of anther development, flavonoids are distributed throughout the anther, and it is thought that transport of flavonoids may occur not only into the locule, but also further into the anther. The genes encoding enzymes of the flavonoid biosynthetic pathway are also expressed in pollen during early development. It is known that flavonoid deficiency in pollen induces male sterility and inhibition of pollen germination in maize and petunia (Mo et al. 1992; Napoli et al. 1999; van der Meer et al. 1992), although the exact mechanism remains unclear. Flavonols also have stimulatory effects on pollen development, germination and tube growth in tobacco (Ylstra et al. 1992). Flavonoid diversity in pollen grains is often high (Wiermann and Gubatz 1992). The principal flavonoids in pollen are frequently 3diglycosides and 3-triglycosides of kaempferol,

Abbreviations: ANS, anthocyanidin synthase; CHI, chalcone isomerase; CHS, chalcone synthase; DFR, dihydroflavonol 4-reductase; F3H, flavanone 3-hydroxylase; F3'H, flavonoid 3'-hydroxylase; F3'5'H, flavonoid 3',5'-hydroxylase; FLS, flavonol synthase; FNSII, flavone synthase II; HPLC, high performance liquid chromatography; RACE, rapid amplification of cDNA ends

The nucleotide sequences reported in this paper have been submitted to DDBJ under accession numbers AB587658 and AB587659.

${ }^{\dagger}$ The authors contributed equally to this work.

This article can be found at http://www.jspcmb.jp/ 
quercetin, and isorhamnetin (Deboo et al. 1995; Wiermann and Gubatz 1992; Zerback et al. 1989).

The flavonoid biosynthetic pathway and the biosynthetic genes were identified by mutant analyses in maize kernels, petunia and snapdragon flowers, and Arabidopsis seed coats (Winkel 2006). Flavonols are produced via a branch of the flavonoid biosynthetic pathway (Figure 1). Chalcone synthase (CHS) catalyzes the initial step in flavonoid biosynthesis and forms chalcones. The chalcones are isomerized by chalcone isomerase (CHI) into flavanones. Hydroxylation of flavanones leads to the production of dihydroflavonols by catalytic reaction of flavanone 3-hydroxylase (F3H). The conversion of dihydroflavonols to flavonols is catalyzed by a dioxygenase, flavonol synthase (FLS).

In anthers and pollen of petunia and maize, several flavonoid biosynthetic genes were isolated and characterized (Deboo et al. 1995; Pollak et al. 1993; van Tunen et al. 1989, 1990, 1991). In maize, $F 3 H$ transcript accumulation is coordinated with the appearance of flavonols in anthers (Daboo et al. 1995). In contrast, flavonol accumulation in petunia and potato is initiated by $C H S$ expression (Pollak et al. 1993; van Eldik et al. 1997). Similarly, the key enzymatic gene in flavonoid biosynthesis in anthers differs among plant species. In addition, the deficiency of flavonols in anthers of maize and petunia is known to induce male sterility (Mo et al. 1992; Taylor and Helper 1997; Taylor and Jorgensen 1992). Anther-specific suppression of $C H S$ transcripts in transgenic petunia and tobacco also resulted in male sterility (Matsuda et al. 1997; van der Meer et al. 1992). Therefore, flavonols accumulated in anthers were thought to play an important role in anther and pollen development. However, in recent years, few studies have investigated flavonol function in anthers.

Japanese gentian is one of the most important floricultural plants in Japan, and typically produces vivid blue flowers. Flower pigmentation in gentian has been well studied. Anthocyanin structure and almost all flavonoid biosynthetic genes except for flavonol synthase have been identified and characterized (Fujiwara et al. 1999; Fukuchi-Mizutani et al. 2003; Goto et al. 1982; Hosokawa et al. 1995, 1997; Kobayashi et al. 1998; Nakatsuka et al. 2005, 2008; Tanaka et al. 1996). Temporal and spatial expression profiles of these flavonoid biosynthetic genes were analyzed in gentian petals (Nakatsuka et al. 2005). Although we produced transgenic gentian plants with modified flower colors (Nishihara et al. 2008), it is necessary to establish male sterile lines for practical use. Flavonol deficiency in anthers by molecular engineering is one technique to induce male sterility. However, the accumulation profiles

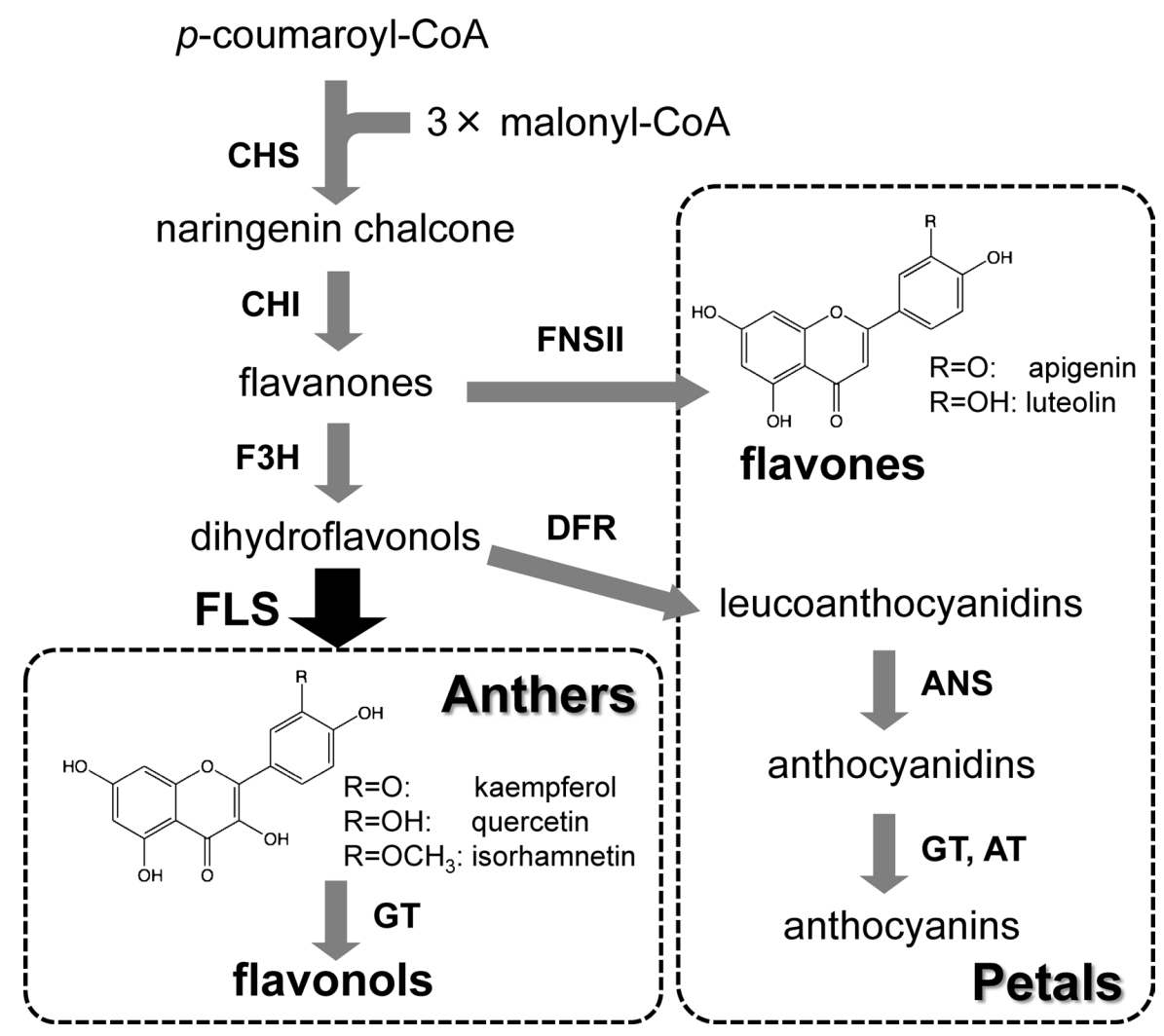

Figure 1. Flavonoid biosynthetic pathway in gentian. Anthers accumulate flavonol derivatives abundantly, while petals accumulate flavone and anthocyanin derivatives. CHS, chalcone synthase; CHI, chalcone isomerase; F3H, flavanone 3-hydroxylase; FLS, flavonol synthase; FNSII, flavone synthase II; ANS, anthocyanidin synthase; GT, glycosyltransferase; AT, acyltransferase. 
of flavonoid components and expression of their biosynthetic genes in gentian anthers have not been characterized. In the present study, we cloned a FLS gene expressed in Japanese gentian anthers and investigated temporal expression profiles of the flavonoid biosynthetic genes in gentian anthers. It was revealed that flavonol accumulation was controlled by antherspecific expression of the $F L S$ gene in Japanese gentian.

\section{Materials and methods}

\section{Flavonoid analysis}

Flavonoid analyses were performed as described by Nakatsuka et al. (2005). Flavonoids from anthers and petals of Gentiana triflora $\times$ G. scabra cv. 'Albireo' were extracted with $80 \%$ (v/v) methanol. To analyze flavonol aglycones, $3 \mathrm{~N} \mathrm{HCl}$ was added to the extract and incubated at $100^{\circ} \mathrm{C}$ for $90 \mathrm{~min}$. The hydrolyzed solution was extracted twice with ethyl acetate, and the ethyl acetate fraction was evaporated and re-dissolved in $80 \%$ methanol. HPLC (D-7000 HPLC system manager, Hitachi, Tokyo, Japan) was carried out with a reversed-phase column (J'sphere ODS-M80, $4.6 \mathrm{~mm} \times 150 \mathrm{~mm}$; YMC, Tokyo, Japan), with a gradient elution of $40-70 \%(\mathrm{v} / \mathrm{v})$ methanol containing $3 \%(\mathrm{v} / \mathrm{v})$ acetic acid for $20 \mathrm{~min}$, followed by an isocratic elution of $70 \%(\mathrm{v} / \mathrm{v})$ methanol containing $3 \%(\mathrm{v} / \mathrm{v})$ acetic acid for $4 \mathrm{~min}$ at a flow rate of $0.8 \mathrm{~mL} \mathrm{~min}^{-1}$ at $40^{\circ} \mathrm{C}$. Flavones and flavonols were quantified by monitoring the peak absorbance at $330 \mathrm{~nm}$ and $360 \mathrm{~nm}$, respectively, against authentic standards.

\section{Isolation of a FLS gene}

A FLS gene was isolated from anther cDNA of G. triflora cv. 'Maciry' by degenerate PCR as described by Nakatsuka et al. (2005). cDNA was synthesized from total RNA extracted from anthers using the RNA PCR Kit (AMV) ver. 3.0 (Takara Bio, Otsu, Japan) using oligo-dT adaptor primers. The degenerate primers (see Table 1) were designed from the conserved amino acid sequences of FLS genes from several plant species, including Petunia hybrida (Z22543), Solanum tuberosum (X92178), Malus domestica (AF119095), Eustoma russellianum (AF240764), and Citrus unshiu (AB011796). The amplified fragments were subcloned into the pCR2.1 TA cloning vector (Invitrogen, Carlsbad, CA, USA) and sequenced using the Big Dye Terminator ver. 1.1 cycle-sequencing kit and an ABI 3130xl genetic analyzer (Applied Biosystems, Tokyo, Japan). To identify the full-length GtFLS cDNA, we employed rapid amplification of cDNA ends (RACE). 5'-RACE was performed with the 5' RACE System ver. 2.0 (Invitrogen) according to the manufacturer's instructions using primer sets listed in Table 1. 3'-RACE was performed using the RNA PCR Kit (AMV) ver. 3.0 using the GtFLS-specific primer listed in Table 1 and the M13-M4 primer. The amplified fragments were subcloned into the pCR4 TOPO TA cloning vector (Invitrogen) and sequenced as described above.

\section{Expression analysis of flavonoid biosynthetic genes in anthers}

Total RNA was isolated from anthers and petals at four developmental stages as defined by Nakatsuka et al. (2005), and leaf and stem samples of cv. 'Albireo' with the Fruit-mate for RNA Purification reagent (Takara Bio). To investigate the expression profiles of flavonoid biosynthetic genes in the samples, northern blot analysis was performed as described by Nakatsuka et al. (2005). The GtFLS probe was prepared with the PCR-DIG Probe Synthesis Kit (Roche Diagnostics, Basel, Switzerland) using the open reading frame (ORF) isolation primer set listed in Table 1. Hybridization and detection were performed as described previously (Nakatsuka et al. 2005).

\section{Isolation of 5'-upstream region of GtFLS and vector construction}

The 5'-upstream region of GtFLS was identified using inverse PCR technology. Genomic DNA $(1 \mu \mathrm{g})$ of G. triflora cv. 'Maciry' was digested by the restriction enzyme EcoRI and self-ligated with the Takara DNA Ligation Kit ver. 3.0 (Takara Bio). Inverse PCR was performed as described by Nakatsuka et al. (2008) using the primer set listed in Table 1. About $4.0 \mathrm{~kb}$ of the amplified fragment was subcloned into the pCR4 TOPO TA cloning vector and sequenced as described above. The GtFLS promoter region containing the first eight amino acid residues was amplified using the promoter isolation primer set listed in

Table 1. Primers used in this study

\begin{tabular}{|c|c|c|}
\hline & & Sequences $\left(5^{\prime} \rightarrow 3^{\prime}\right)$ \\
\hline \multirow[t]{2}{*}{ Degenarete PCR } & Forward & YTICCICARGARGARAARGA \\
\hline & Reverse & GGIGGRTARTARTTDATYTT \\
\hline \multirow[t]{2}{*}{$5^{\prime}-\mathrm{RACE}$} & $1 \mathrm{st}$ & AACCAAGTCATCACCACCAG \\
\hline & nested & GTACATGAACATCTTGTCCACCAC \\
\hline $3^{\prime}-\mathrm{RACE}$ & Forward & GGAAGGATCTCAAAGCATTG \\
\hline \multirow[t]{2}{*}{ ORF isolation } & Forward & ATGGAGGAAAAGAGAGTACAAGAAATTTC \\
\hline & Reverse & TCACTGAGGTAGCTTATTAAGCTTGCAA \\
\hline \multirow[t]{2}{*}{ Inverse PCR } & Forward & CAAGTAAAGAATGGGGGTTATTTCAAGTTGTG \\
\hline & Reverse & TTCAGCTGGTATTGTGTCCAGTACATTGGATG \\
\hline \multirow[t]{2}{*}{ Promoter isolation } & Forward & CCTGCAGGATATTTGTAATACATGTTACATGG \\
\hline & Reverse & GCTCTAGATACTCTCTTTTCСТCСАTTATTTTTTTAGTTCTCTCAATTGC \\
\hline
\end{tabular}


Table 1 and a plasmid obtained by inverse PCR as a template. The GtFLS promoter (GtFLSpro) was substituted for the Cauliflower mosaic virus (CaMV) 35S promoter in a modified pBI221 vector (Clontech, Mountain View, CA, USA). The GtFLSproGUS cassette was inserted into a binary vector, pSMAB704 (Igasaki et al. 2002), harboring the bialaphos herbicide resistance (bar) gene. pSMABR-GtFLSproGUS was introduced into Agrobacterium tumefaciens strain EHA101 (Hood et al. 1986) by electroporation and used for plant transformation as outlined below.

\section{Production of GtFLSproGUS-expressing transgenic plants}

Three plant species, comprising tobacco, Arabidopsis and gentian, were transformed with the binary construct pSMABRGtFLSproGUS. Tobacco plants were transformed via an $A$. tumefaciens-mediated leaf disc procedure (Horsch et al. 1985), and selected using a regeneration medium containing $5 \mathrm{mg}^{-1}$ bialaphos. After rooting and acclimatization, 15 lines of regenerated plants were grown in a greenhouse and set seed by self-pollination. Preliminary screening of the primary transgenic lines with a histochemical GUS assay was performed. Two representative transgenic $T_{1}$ plant lines selected on $5 \mathrm{mgl}^{-1}$ bialaphos-containing medium were transferred to soil, and then used for histochemical and fluorometric GUS assays. Arabidopsis transformation employed the floral dip technique (Clough and Bent, 1998), and four $T_{1}$ transformants were selected on medium containing $6 \mathrm{mgl}^{-1}$ bialaphos and subjected to the histochemical GUS assay. Gentian transformation was performed as described by Nishihara et al. (2006). Bialaphos-resistant shoots were transferred onto root-inducing medium. Nine lines of transgenic $\mathrm{T}_{0}$ plants were grown in a closed greenhouse, and their floral organ samples were subjected to the histochemical GUS assay.

\section{Histochemical and fluorometric GUS assays in transgenic plants}

Histochemical and fluorometric GUS assays were performed using a modified protocol of Jefferson (1987). For detecting the localization of GUS activity, plant tissues were incubated in $90 \%$ acetone on ice for $30 \mathrm{~min}$, then incubated in X-Gluc buffer solution $\left(0.5 \mathrm{mg}^{-1}\right.$ 5-bromo-4-chloro-3-indolyl- $\beta$-glucuronic acid, $10 \mathrm{mM}$ sodium phosphate $[\mathrm{pH} 7.0], 0.5 \mathrm{mM}$ potassium ferrocyanide, $0.5 \mathrm{mM}$ potassium ferricyanide, $20 \%$ methanol and $0.3 \%$ Triton $\mathrm{X}-100$ ) at $37^{\circ} \mathrm{C}$ for $16 \mathrm{~h}$. In the above buffer, $20 \%$ methanol is effective in reducing endogenous GUS activity (Kosugi et al. 1990). After bleaching with 70\% ethanol, the tissues were observed with a compound microscope.

Crude proteins from each sample were extracted with MUG extraction buffer $(50 \mathrm{mM}$ sodium phosphate $[\mathrm{pH} 7.0], 10 \mathrm{mM}$ EDTA, $0.1 \%$ Triton X-100, 0.1\% N-laurylsarcosine sodium salt and $10 \mathrm{mM} \beta$-mercaptoethanol). The reaction mixture $(200 \mu \mathrm{l})$, comprising extracted protein and $1 \mathrm{mM} 4$-methylumbelliferyl$\beta$-D-glucuronide (MUG), was incubated at $37^{\circ} \mathrm{C}$. Fluorescence was measured with excitation at $365 \mathrm{~nm}$ and emission at 455 $\mathrm{nm}$ on a Gemini Max fluorescent microplate reader (Molecular Devices, Sunnyvale, CA, USA). Protein concentrations were measured as described by Bradford et al. (1976).

\section{Results and discussion}

\section{The accumulation of flavonol derivatives in gentian anthers}

In a previous study of the flavonoid composition of cultivated Japanese gentian plants, we reported that both anthocyanin and flavone derivatives accumulated abundantly in the petals, whereas flavonol derivatives were hardly detected (Nakatsuka et al. 2005). The four stages defined during flower development were also used in the present study to provide reference points for flavonoid accumulation (Figure 2A, B). The anthers at floral development stages 1 (S1) and 2 (S2) contained binucleate pollen grains, and those at stage 3 (S3) contained trinucleate grains (data not shown). The anthers at stage 4 (S4) dehisced and released the mature, three-celled pollen grains (Figure 2B). In nearly $70 \%$ of flowering plants, pollen grains are shed at the two-celled stage, whereas in the remaining species they are shed at the three-celled stage (Brewbaker 1967). HPLC analysis of methanol extracts from anthers exhibited five major peaks (peaks 1 to 5) presumed as flavonols with maximum absorption at $350-360 \mathrm{~nm}$ (Supplemental Figure S1). Hydrolysis analyses confirmed that these peaks were composed of flavonol glycosides, but not flavonol aglycones, although the structures of flavonol glycosides at each peak were unknown. Therefore, we analyzed the amounts of flavonol aglycones after hydrolysis with hydrochloric acid in this study. Flavonols were the flavonoid compounds accumulated in the anthers, and increased slightly throughout anther development (Figure 2). The flavonols in the anthers comprised kaempferol, quercetin and isorhamnetin derivatives (Figure 2, Supplemental Figure S1). Anthocyanins and flavones, which accumulated mainly in the petals, were not detected in the anthers (data not shown). Quercetin and isorhamnetin derivatives accumulated to higher concentrations in anthers than did kaempferol derivatives (Figure 2). Although isorhamnetin is a methylated flavonol, methylated flavones and methylated anthocyanins were not detected in any gentian organs (Nakatsuka et al. 2005, data not shown). Therefore, FLS and methyltransferase activities were indicated to be specific to the anthers in gentian plants. These results revealed that distinctly different flavonoid compounds accumulated in gentian anthers and petals, namely flavonols and flavones as unpigmented compounds. Pollen grains of higher plants accumulate mostly flavonol derivatives, which are frequently 3diglycosides and 3-triglycosides of kaempferol, quercetin and isorhamnetin (Wiermann and Gubatz 1992). Major flavonoids of petunia pollen grains are quercetin and kaempferol 2-O-(2'-O- $\beta$-D-glucopyranosyl)- $\beta$-galactropyranoside (Zerback et al. 1989). In maize anthers, quercetin was the most abundant flavonol, with smaller 

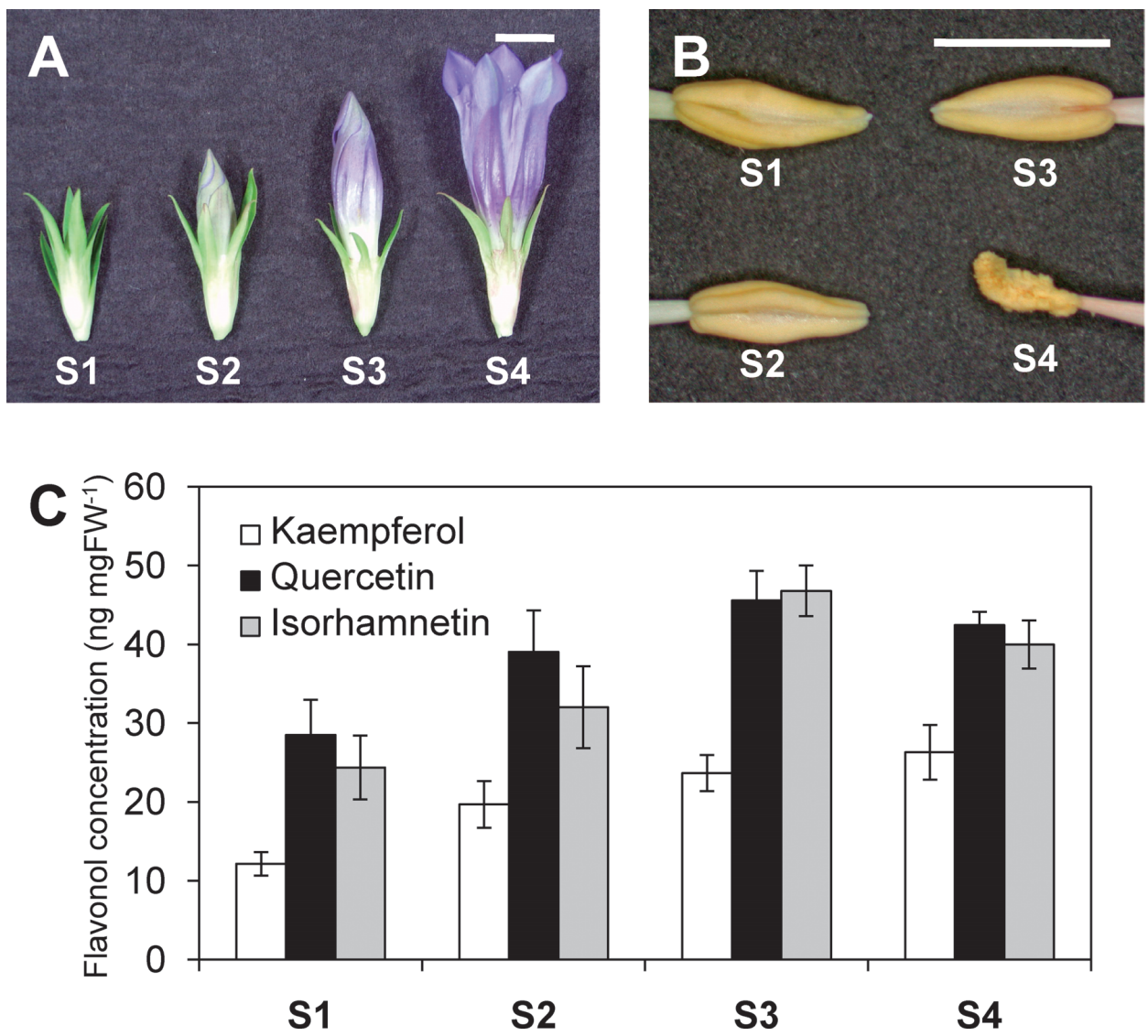

Figure 2. Flavonol accumulation profiles in gentian anthers. (A) Four gentian floral developmental stages as defined by Nakatsuka et al. (2005), and (B) anthers of each stage. Scale bar=1 cm (A) and $5 \mathrm{~mm}$ (B). (C) Flavonols were extracted from anther samples at four developmental stages with $80 \%(\mathrm{v} / \mathrm{v})$ methanol and then hydrolyzed. The chemical structures of kaempferol, quercetin and isorhamnetin are indicated in Figure 1. FW, fresh weight.

amounts of isorhamnetin and traces of kaempferol (Deboo et al. 1995). The structure of flavonol glycoside(s) of gentian anthers should be identified in future studies.

\section{Isolation of a FLS gene from gentian anthers}

As mentioned above, flavonoid analysis revealed that flavonol derivatives specifically accumulate abundantly in gentian anthers. Therefore, we attempted to isolate a $F L S$ gene from gentian anthers. Using degenerate PCR and RACE technology, one FLS homologue was identified. The GtFLS cDNA (DDBJ accession number AB587658) was $1,267 \mathrm{bp}$ in length and contained an ORF encoding 333 deduced amino acid sequences. The deduced amino acid sequences of GtFLS exhibited 78.9, 70.9 , and $69.9 \%$ identities with those of petunia (Z22543; Holton et al. 1993), apple (AY965343; Halbwirth et al. 2006) and Citrus unshiu (AB011796; Moriguchi et al. 2002), respectively. FLS belongs to the 2-oxoglutarate-dependent dioxygenase family, along with anthocyanidin synthase (ANS) and F3H. GtFLS contained characteristic conserved motifs (data not shown), including two histidines and one aspartic acid as part of the putative iron-binding site, and an arginine residue as a part of the 2-oxoglutarate binding site (Lukacin and Britsch 1997). Therefore, the isolated GtFLS gene was concluded to be a FLS ortholog, although the enzymatic properties of GtFLS remain to be determined.

\section{Anther-specific expression of the FLS gene}

To identify the regulatory mechanism for the different flavonoid components of the anthers and petals in gentian, we investigated the spatial and temporal expression of flavonoid biosynthetic structural genes (Figure 3) as performed by Nakatsuka et al. (2005). Northern blot analysis revealed that only a restricted number of flavonoid biosynthetic genes were expressed in the anthers. Transcripts of CHS, CHI, F3H and FLS, which are so-called 'early' flavonoid biosynthetic genes (i.e. encoding enzymes functioning at early steps in the flavonoid biosynthetic pathway), were detected at all four floral development stages analyzed in this study. CHS, $F 3 H$ and $F L S$ transcripts were expressed constantly in anthers throughout flower development, whereas the expression of $\mathrm{CHI}$ decreased after floral development stage S3. The transcripts of FNSII, encoding a key 


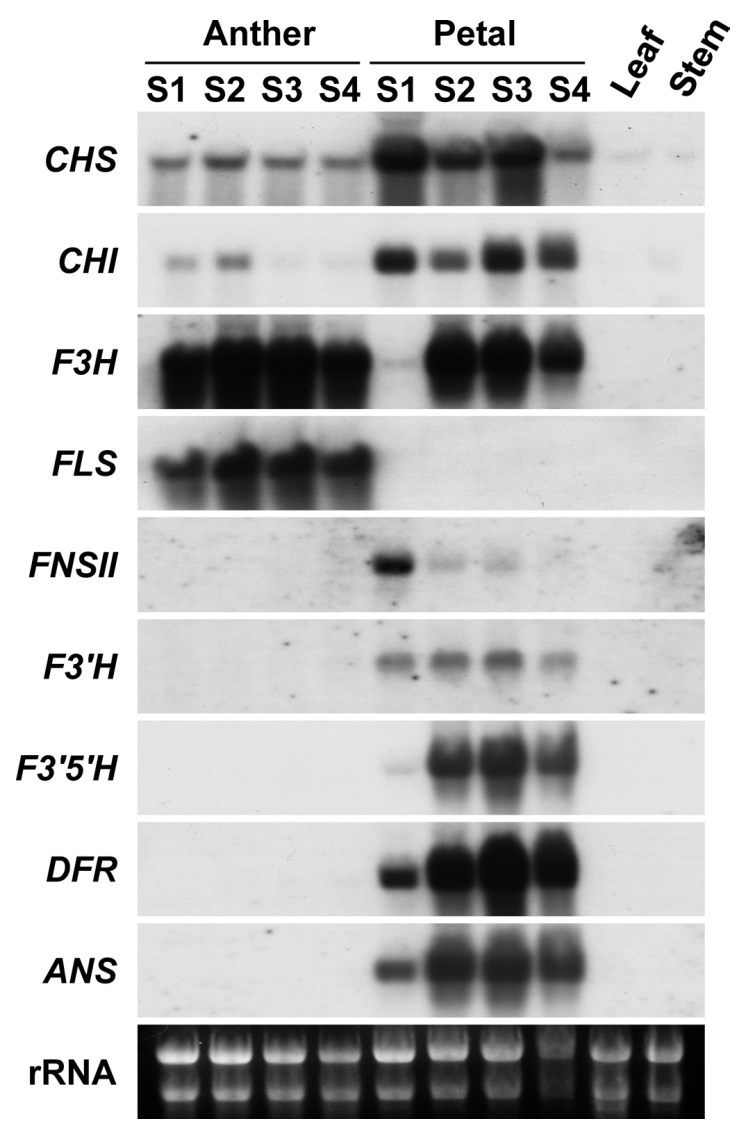

Figure 3. Expression analysis of flavonol biosynthetic genes in gentian plants. Total RNA from anthers and petals at four floral development stages (S1 to S4), leaves and stems were loaded in each lane. Probes used for northern blot analyses are specified on the left of each panel. Ethidium bromide-stained ribosomal RNA bands are shown as a control.

enzyme for flavone biosynthesis, and 'late' flavonoid biosynthetic genes, such as $F 3^{\prime} 5^{\prime} H, D F R$ and $A N S$, were not detected at all in anthers, although these genes were expressed abundantly in petals. Notably, expression of $F L S$ was detected only in anthers and not in petals. In maize, $\mathrm{F} 3 \mathrm{H}$ transcript accumulation was coordinated with the appearance of flavonols in anthers (Daboo et al. 1995). In addition, flavonol accumulation in petunia and potato were initiated by expression of CHS (Pollak et al. 1993; van Eidik et al. 1997). In gentian, it was demonstrated that two branches of the flavonoid biosynthetic pathway, namely flavonol biosynthesis in the anthers and flavone biosynthesis in the petals, are regulated by the spatial-specific expression of FLS and FNSII, respectively. Although accumulation of quercetin and isorhamnetin derivatives was detected in gentian anthers, expression of $F 3^{\prime} H$, which encodes an enzyme catalyzing the hydroxylation of flavonoids at the $3^{\prime}$ end, was not detected in the anther (Figure 3). Therefore, it is likely that a different specific hydroxylase for flavonol exists in gentian anthers.
Isolation and characterization of GtFLS promoter

To gain insights into the spatiotemporal pattern of GtFLS expression in gentian anthers, we isolated the $5^{\prime}$-flanking region of GtFLS by inverse PCR. A 916 bp fragment (nucleotide -845 to +71 ) of GtFLS was amplified and used as the GtFLS promoter (GtFLSpro, DDBJ accession number AB587659). The sequence contained the 5' untranslated region (UTR) and initial six amino acid residues (MEEKRV) (Figure 4). A putative TATA box is present $30 \mathrm{bp}$ upstream of the transcription start site. Cisregulatory motifs of the upstream region of GtFLS were searched using PLACE (Higo et al. 1998). As a result, various cis-acting regulatory elements known to be involved in anther/pollen-specific expression were detected in the promoter region of GtFLS (Figure 4). Two motifs, GTGANTG10 (GTGA; Twell et al. 1991) and POLLEN1LeLAT52 (AGAAA; Bate and Twell 1998), were found in forward or reverse directions at multiple sites. The GtFLS promoter also contained a putative anther box (60\% identity) $709 \mathrm{bp}$ upstream to the transcription start site. The anther box was proposed from comparison of the promoter of flavonoid genes that are active in immature anthers of petunia (van der Meer et al. 1992; van Tunen et al. 1989). A deletion assay of the CHS promoter of petunia showed that the anther box is not a prerequisite for anther-specific gene expression (van der Meer et al. 1990). This suggests that the additional sequence within the GtFLS promoter directs the organ-specific expression.

\section{GUS expression of GtFLSproGUS-expressing transgenic plants}

To investigate the localization and intensity of GtFLS expression, we produced GtFLSproGUS transgenic plants in three species, namely tobacco, Arabidopsis and gentian. In 14 primary transgenic tobacco lines, eight lines showed blue staining in anthers. We chose two strongly stained lines and produced $\mathrm{T}_{1}$ plants by selfpollination for detailed analyses. The results of a typical transgenic tobacco $T_{1}$ plant line (no. 14) are shown in Figure 5. Tobacco anther samples were collected at several floral development stages as defined by Koltunow et al. (1990). The fluorometric GUS assay indicated that GUS activity was detected predominantly in the anthers of the transgenic tobacco plants (Figure 5A, Supplemental Figure S2). Expression was extremely low or absent in other organs, including the petal, pistil, sepal, leaf, and stem samples (Figure 5A). Anthers at developmental stage 1 (S1), in which all major anther tissues have been specified, showed GUS activity, but the activity decreased over the course of anther development up to stage 6 (Figure 5A). Thereafter, GUS activity increased considerably at developmental stage 9 , at which point degraded connective tissues separate the pollen sac. The GUS activity profile determined here 


\begin{tabular}{|c|c|}
\hline -845 АТАTTTGTAАTACATG & -830 \\
\hline TACATGGTACGGCCTGCTTCGGCTTTCCATTGCAACTATGGTACGACСTACTTAATTAT & -770 \\
\hline GGGCATGCAATACACACATCTTATCCATACATTAAAGTGTACTACTTTAAATGTGTGGAT & -710 \\
\hline $\begin{array}{c}\text { AAGATGTAAGGGCACT CCAGTAGAGTCCCCAAATTTTATCCCTAAAATAATATAAAATA } \\
\text { Anther box }\end{array}$ & -650 \\
\hline АТАСАТАТСССТАТTTТАСААСАТСТСААТTСАААААССТСТАСААСАGСАТСТСТАТСС & -590 \\
\hline $\begin{array}{c}\text { ТТАТСССТАТААСАТТТСАААТААТАТТАААТААТАСАТАТТСТАССТСАСААСССТАТТ } \\
\text { GTGA }(-)\end{array}$ & -530 \\
\hline $\begin{array}{c}\text { TATACGCATTAAATATTTATTATTTCACTCCAGCAGCATCCCTATCCATATCCCTATAAT } \\
\text { GTGA(-) }\end{array}$ & \\
\hline $\begin{array}{c}\text { TTTTAАTAАTTAАATATGTTTAGAGCAGTGAATAGTGCATCCACACAAGTAGGGATGCAC } \\
\text { GTGA(+) }\end{array}$ & -410 \\
\hline TGTTCATATTCCTAAAAAATAATAAATAGGGATAGAGCATCAGCTGTATGAGCTATTTAA & -350 \\
\hline GTСАAААСTСТААTTTGTTATСTTCATTTTAGGAATAAGGCACCGTATAGAGСTTCTGCT & -290 \\
\hline GGAAGTGCCСTAAATGTGTGGATAAGATGTGTGTAGTATATACGGACTACACATTATGTG & -230 \\
\hline TAGTGAATATATCACCAAGTCAACTCCTGTATCAGGTGTACTAAAACCACCCACGTGGTT & -170 \\
\hline GTGA $(+) \quad$ GTGA $(-)$ & -) \\
\hline $\begin{array}{l}\text { TCTTCACGTAATGCTGCTTGCATGACGATCATTTTGTTTTAATTTCTTAAAAAAACTCCA } \\
\begin{array}{ll}\text { GTGA }(-) & \text { LAT52(-) }\end{array}\end{array}$ & -110 \\
\hline $\begin{array}{c}\text { TCСАСТСССТССTCTCTTTTTTTTTCCTCACCTTTTTCTTGGTTTGTTACAAAAGTTGCT } \\
\text { GTGA(-) LAT52(-) }\end{array}$ & -50 \\
\hline TCCGTTTCCTACGCCTTCQTATAATTAAGTACCTACCCAAАCTAATTTTCtcacaccatc & +11 \\
\hline atctctttgttaatatctgcaattgagagaactaaaaaaataATGGAGGAA & +7 \\
\hline $\begin{array}{llllll}M & \mathrm{E} & \mathrm{E} & \mathrm{K} & \mathrm{R} & \mathrm{V}\end{array}$ & \\
\hline
\end{tabular}

Anther box

Gentian FLS : AAGATGTAAGGGCACT

Petunia FLS : TAGAGGWGAMRDARWT

$* * * * * * * * *$

Figure 4. Nucleotide sequence of the 5'-upstream region of GtFLS. The GtFLS promoter and translated region are indicated in upper case. The 5' UTR is indicated in lower case. The bent arrow indicates the transcription start site. A putative TATA box is enclosed in a box. The motifs of GTGANTG10 (GTGA), POLLEN1LeLAT52 (AGAAA) and the anther box are highlighted in bold, underlined and in bold, respectively. The putative anther box is enclosed in a box with double lines, and alignment of the gentian and petunia sequences is shown below.

almost corresponded with the accumulation profile of flavonol derivatives in tobacco anthers (Supplemental Figure S3A).

The histochemical GUS assay yielded similar results to the fluorometric assay of GUS activity. The tobacco anther comprises, from the inside to the outside, a vascular bundle (V) surrounded by parenchymatic cells of the connective (Co), four locules containing the sporogenenic tissue (pollen), the tapetum $(\mathrm{T})$, and the endothecium (En) (Figure 5B). At anther developmental stage 1, strong blue staining indicating GUS expression was observed in the vascular bundle, tapetum and circular cell cluster (CCC) (Figure 5B). Microspores started to be stained slightly at anther developmental stage 3 (Figure 5C). Interestingly, GUS staining was reduced at stages 3 and 6 (Figure 5C, D). However, at stage 9, strong staining was observed in all anther tissues, including the pollen grains (Figure 5E). A similar GUS staining pattern was obtained in the other transgenic tobacco line (Supplemental Figure S2).

Four lines of transgenic Arabidopsis plants carrying the same binary vector were analyzed for GUS activity. The results for the typical line no. 2 are shown in Figure 6A-D. Anther samples were collected at several floral development stages as defined by Smyth et al. (1990). GUS expression commenced at about stage 9 and continued during the later stages of anther development (stages 9 to 15, Figure 6A-D). GUS expression was 

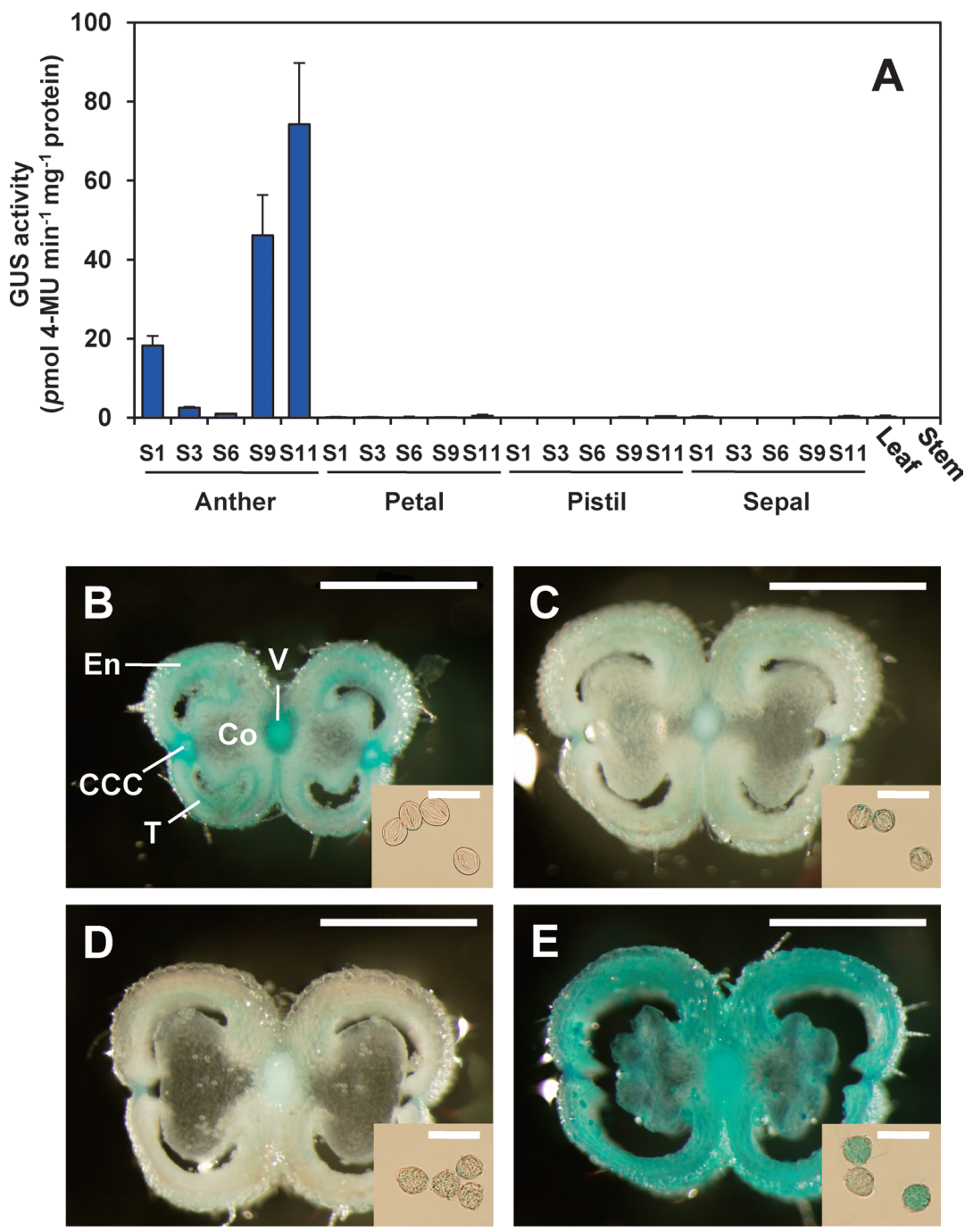

Figure 5. Fluorometric and histochemical GUS assays in GtFLSproGUS-introduced tobacco plants. (A) Enzymatic GUS activities were determined fluorometrically in different organs at several developmental stages in the representative transgenic tobacco line no. 14. Values indicate the mean \pm standard deviation of four experiments. (B-E) Histochemical assay of GUS staining in anthers and pollen of transgenic tobacco line no. 14. The anthers were stained with 5-bromo-4-chloro-3-indolyl- $\beta$-D-glucuronide (X-Gluc) solution at $37^{\circ} \mathrm{C}$ for $16 \mathrm{~h}$ for the localization of cells expressing the GUS reporter gene. The insets show pollen grains at higher magnification. Cross-sections of anthers are shown at floral development stage S1 (B), S3 (C), S6 (D) and S9 (E). Scale bar=1 mm for anthers and $50 \mu \mathrm{m}$ for pollen grains. Co, connective; CCC, circular cell cluster; En, endothecium; $\mathrm{T}$, tapetum; $\mathrm{V}$, vascular bundle.

observed in tapetum tissue at about stages 9 to 10 (Figure 6A) and increased as the anther matured (Figure $6 \mathrm{~B}, \mathrm{C})$. At about floral stage 13, when the anthers dehisced, strong staining indicating GUS expression was observed in the pollen grains (Figure 6D). No GUS expression was detected in vegetative tissues, except for slight staining in two-day-old seedlings (data not shown). The other three transgenic Arabidopsis lines showed a similar GUS staining pattern, with slightly different expression levels (Supplemental Figure S4).

In tobacco anthers, the accumulation of flavonols, including kaempferol and quercetin derivatives, were first detected at developmental stage 6 , and increased throughout anther development (Supplemental Figure $\mathrm{S} 3 \mathrm{~A})$. Maximum expression of $\mathrm{NtCHS}, \mathrm{NtF} 3 \mathrm{H}$ and
NtFLS occurred at developmental stages 4 to 6 , prior to flavonol accumulation (Supplemental Figure S3B, D, F). $N t F L S$ was expressed slightly at developmental stages 1 and 2 , increased at stages 4 to 6 , and began to decrease at stage 7 , when the tapetum was degraded in the anther (Supplemental Figure S3F). The GUS activity profile in GtFLSproGUS-transgenic tobacco was not coincident with the temporal and spatial expression profile of $N t F L S$. In tobacco, flavonols were distributed throughout the whole plant (data not shown), whereas gentian showed restricted flavonol accumulation only in the anthers. Therefore, the GtFLS promoter might be controlled by other trans factors, differing from those for NtFLS. The Arabidopsis genome contains AtFLS1 and five FLS-like (AtFLS2-O), which show no FLS activity, 

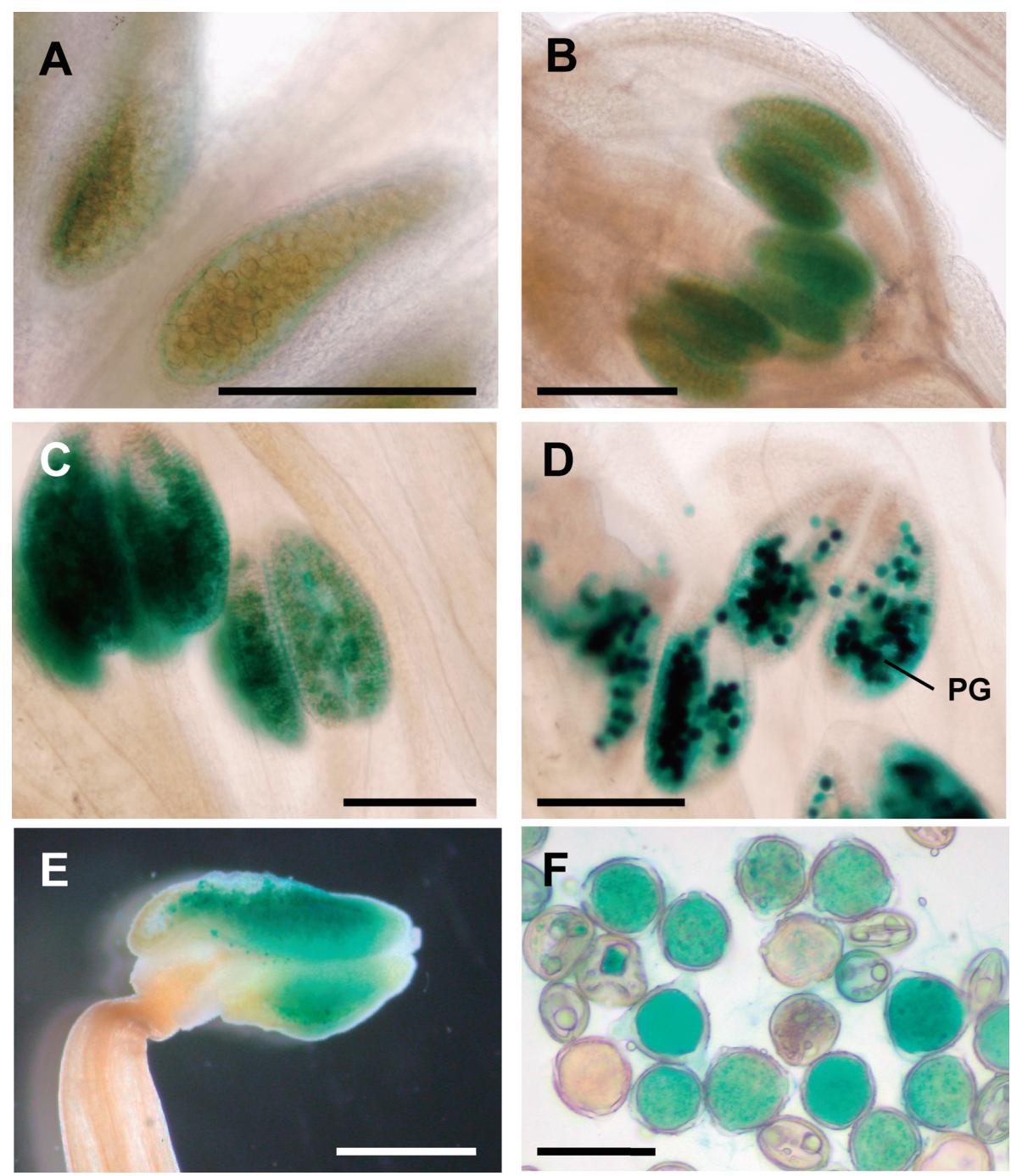

Figure 6. Histochemical GUS assay in GtFLSproGUS transgenic Arabidopsis and gentian plants. (A-D) Series of developing florets in GtFLSpGUS-introduced Arabidopsis plant line no. 2. GUS expression was initiated in the tapetum at about floral development stage 9 (A) and increased as the anther matured; stages 11 (B) and 12 (C) are shown. In dehisced anthers at stage 13, strong GUS expression was observed in the pollen grains (D). Blue staining indicating GUS expression was observed in the anther (E) and pollen grains (F) of transgenic gentian plants just before anthesis. Scale bar $=100 \mu \mathrm{m}$ (A to D), $1 \mathrm{~mm}$ (E) and $50 \mu \mathrm{m}$ (F). PG, pollen grain.

and AtFLS was expressed not only in stamens but also in other tissues such as petals and siliques (Owens et al. 2008). However, the GtFLSproGUS transgenic tobacco and Arabidopsis plants demonstrated that anther-specific expression of the GtFLS promoter occurred in both plants.

Six out of nine transgenic gentian lines produced flowers, and were subjected to the histochemical GUS assay. Four lines showed strong GUS expression, which was observed predominantly in anthers (Figure 6E). Blue staining of pollen grains was observed in gentian as in tobacco and Arabidopsis (Figure 6F). No staining was detected in other organs (data not shown). Because the transgenic gentian plants set few flowers in the current year, detailed analyses during anther development could not be performed in this study. GUS expression in GtFLSproGUS transgenic plants, both in anthers and pollen, is not surprising, because flavonoids in the anther are thought to be synthesized in the tapetum tissue and also in microspores (Taylor and Helper 1997). As mentioned above, a difference in temporal and spatial expression of GUS between tobacco and Arabidopsis transformants was observed. The reason for this is not clear, but future analyses of the transgenic gentian plants will provide additional information on the different mechanisms underlying anther-specific expression of $F L S$ in plants.

The promoters that control anther-specific gene expression are useful because they can be utilized to induce male fertility, an important trait in crop breeding (Peremarti et al. 2010). Numerous anther and pollenspecific promoters have been identified in a variety of plants, including the TA29 promoter from tobacco (Koltunow et al. 1990), the $A 9$ promoter from 
Arabidopsis (Paul et al. 1992), the LAT52 promoter from tomato (Twell et al. 1990), and the Osg6B promoter from rice (Tsuchiya et al. 1994). Anther-specific promoters have been used successfully to generate male-sterile plants (Mariani et al. 1990). Therefore, anther-specific expression of a cell death factor gene (such as barnase) driven by the GtFLS promoter might also induce male sterility in transgenic gentian plants. In addition, some flavonol-deficient plants are self-sterile because the pollen grains fail to germinate (Mo et al. 1992; Taylor and Helper 1997; Taylor and Jorgensen 1992), or fail to produce a functional pollen tube (Pollak et al. 1995; Taylor and Helper 1997; Ylstra, 1994). Matsuda et al. (1997) produced partial male sterility in transgenic tobacco by sense and antisense suppression of CHS. To induce flavonol deficiency and male sterility in the anthers of gentian plants, GtFLS would be one of the targets for gene silencing, because GtFLS regulates anther-specific accumulation of flavonols in gentian. Such experiments are currently underway and the results will be presented in a future publication.

\section{Acknowledgements}

The authors thank Ms. A. Kubota, C. Yoshida, Y. Abe and Y. Kakizaki of the Iwate Biotechnology Research Center for their technical support. We also thank Dr. H. Ichikawa of the National Institute of Agrobiological Sciences for providing the pSMAB704 binary vector. This work was supported by the Program for Promotion of Basic and Applied Researches for Innovations in Bio-oriented Industry.

\section{References}

Bate N, Twell D (1998) Functional architecture of a late pollen promoter: pollen-specific transcription is developmentally regulated by multiple stage-specific and co-dependent activator elements. Plant Mol Biol 37: 859-869

Bradford MM (1976) A rapid and sensitive method for the quantitation of microgram quantities of protein utilizing the principle of protein-dye binding. Anal Biochem 72: 248-254

Brewbaker JL (1967) The distribution and phylogenetic significance of binucleate and trinucleate pollen grains in the angiosperms. Amer J Bot 54: 1069-1083

Clough SJ, Bent AF (1998) Floral dip: a simplified method for Agrobacterium-mediated transformation of Arabidopsis thaliana. Plant J 16: 735-743

Deboo GB, Albertsen MC, Taylor LP (1995) Flavanone 3hydroxylase transcripts and flavonol accumulation are temporally coordinate in maize anthers. Plant J 7: 703-713

Fujiwara H, Tanaka Y, Yonekura-Sakakibara K, Fukuchi-Mizutani M, Nakao M, Fukui Y, Yamaguchi M, Ashikari T, Kusumi T (1998) cDNA cloning, gene expression and subcellular localization of anthocyanin 5-aromatic acyltransferase from Gentiana triflora. Plant J 16: 421-431

Fukuchi-Mizutani M, Okuhara H, Fukui Y, Nakao M, Katsumoto Y, Yonekura-Sakakibara K, Kusumi T, Hase T, Tanaka Y (2003) Biochemical and molecular characterization of a novel UDP- glucose: anthocyanin 3'-O-glucosyltransferase, a key enzyme for blue anthocyanin biosynthesis, from gentian. Plant Physiol 132: $1652-1663$

Goto T, Kondo T, Tamura H, Imagawa H, Iino A, Takeda K (1982) Structure of gentiodelphin, an acylated anthocyanin isolated from Gentiana makinori, that is stable in dilute aqueous solution. Tetrahedron Lett 23: 3695-3698

Halbwirth H, Fischer TC, Schlangen K, Rademacher W, Schleifer KJ, Forkmann G, Stich K (2006) Screening for inhibitors of 2-oxoglutarate-dependent dioxygenases: Flavanone 3 betahydroxylase and flavonol synthase. Plant Sci 171: 194-205

Harborne JB, Williams CA (2000) Advances in flavonoid research since 1992. Phytochemistry 55: 481-504

Higo K, Ugawa Y, Iwamoto M, Higo H (1998) PLACE: a database of plant cis-acting regulatory DNA elements. Nucleic Acids Res 26: 358-359

Holton TA, Brugliera F, Tanaka Y (1993) Cloning and expression of flavonol synthase from Petunia hybrida. Plant $J 4$ : $1003-1010$

Hood EE, Helmer GL, Fraley RT, Chilton MD (1986) The hypervirulence of Agrobacterium tumefaciens A281 is encoded in a region of pTiBo542 outside of T-DNA. J Bacteriol 168: 1291-1301

Horsch RB, Fry JE, Hoffmann NL, Eicholtz D, Rogers SG, Fraley RT (1985) A simple method for transferring genes into plants. Science 227: 1229-1231

Hosokawa K, Fukushi E, Kawabata J, Fujii C, Ito T, Yamamura S (1995) Three acylated cyanidin glucosides in pink flowers of Gentiana. Phytochemistry 40: 941-944

Hosokawa K, Fukushi E, Kawabata J, Fujii C, Ito T, Yamamura S (1997) Seven acylated anthocyanins in blue flowers of Gentiana. Phytochemistry 45: 167-171

Igasaki T, Ishida Y, Mohri T, Ichikawa H, Shinohara K (2002) Transformation of Populus alba and direct selection of transformants with the herbicide bialaphos. Bull FFPRI 1: 235-240

Jefferson RA (1987) Assaying chimeric genes in plants: The GUS gene fusion system. Plant Mol Biol Rep 5: 387-405

Kobayashi H, Oikawa Y, Koiwa H, Yamamura S (1998) Flowerspecific expression directed by the promoter of a chalcone synthase gene from Gentiana triflora in Petunia hybrida. Plant Sci 131: 173-180

Koltunow AM, Truettner J, Cox KH, Wallroth M, Goldberg RB (1990) Different Temporal and Spatial Gene Expression Patterns Occur during Anther Development. Plant Cell 2: 1201-1224

Kosugi S, Ohashi Y, Nakajima K, Arai Y (1990) An improved assay for $\beta$-glucuronidase in transformed cells: Methanol almost completely suppresses a putative endogenous $\beta$-glucuronidase activity. Plant Sci 70: 133-140

Lukacin R, Britsch L (1997) Identification of strictly conserved histidine and arginine residues as part of the active site in Petunia hybrida flavanone 3beta-hydroxylase. Eur J Biochem 249: 748-757

Mariani C, De Beuckeleer M, Truettner J, Leemans J, Goldberg RB (1990) Induction of male sterility in plants by a chimaeric ribonuclease gene. Nature 347: 737-741

Matsuda N, Kishitani S, Toriyama K (1997) Antisense and sense CHS cDNA expressed by a tapetum-specific promoter causes partial male sterility in transgenic tobacco. Plant Biotechnol 14: 157-161

Mo Y, Nagel C, Taylor LP (1992) Biochemical complementation of chalcone synthase mutants defines a role for flavonols in 
functional pollen. Proc Natl Acad Sci USA 89: 7213-7217

Moriguchi T, Kita M, Ogawa K, Tomono Y, Endo T, Omura M (2002) Flavonol synthase gene expression during citrus fruit development. Physiol Plant 114: 251-258

Nakatsuka T, Haruta KS, Pitaksutheepong C, Abe Y, Kakizaki Y, Yamamoto K, Shimada N, Yamamura S, Nishihara M (2008) Identification and characterization of R2R3-MYB and bHLH transcription factors regulating anthocyanin biosynthesis in gentian flowers. Plant Cell Physiol 49: 1818-1829

Nakatsuka T, Nishihara M, Mishiba K, Yamamura S (2005) Temporal expression of flavonoid biosynthesis-related genes regulates flower pigmentation in gentian plants. Plant Sci 168: 1309-1318

Nakatsuka T, Sato K, Takahashi H, Yamamura S, Nishihara M (2008) Cloning and characterization of the UDPglucose:anthocyanin 5-O-glucosyltransferase gene from blueflowered gentian. J Exp Bot 59: 1241-1252

Napoli CA, Fahy D, Wang HY, Taylor LP (1999) white anther: A petunia mutant that abolishes pollen flavonol accumulation, induces male sterility, and is complemented by a chalcone synthase transgene. Plant Physiol 120: 615-622

Nishihara M, Nakatsuka T, Hosokawa K, Yokoi T, Abe Y, Mishiba K, Yamamura S (2006) Dominant inheritance of white-flowered and herbicide-resistant traits in trangenic gentian plants. Plant Biotechnol 23: 25-31

Nishihara M, Nakatsuka T, Mizutani-Fukuchi M, Tanaka Y, Yamamura S (2008) Gentians: From gene cloning to molecular breeding. In Jaime $\mathrm{A}$, da Silva $\mathrm{T}$ (eds) Floricultural and Ornamental Biotechnology V. Global Science Books, Middlesex pp 57-67

Owens DK, Alerding AB, Crosby KC, Bandara AB, Westwood JH, Winkel BS (2008) Functional analysis of a predicted flavonol synthase gene family in Arabidopsis. Plant Physiol 147: 1046-1061

Paul W, Hodge R, Smartt S, Draper J, Scott R (1992) The isolation and characterisation of the tapetum-specific Arabidopsis thaliana A9 gene. Plant Mol Biol 19: 611-622

Peremarti A, Twyman RM, Gomez-Galera S, Naqvi S, Farre G, Sabalza M, Miralpeix B, Dashevskaya S, Yuan D, Ramessar K, et al. (2010) Promoter diversity in multigene transformation. Plant Mol Biol 73: 363-378

Piffanelli P, Ross JHE, Murphy DJ (1998) Biogenesis and function of the lipidic structures of pollen grains. Sexual Plant Reproduction 11: 65-80

Pollak PE, Hansen K, Astwood JD, Taylor LP (1995) Conditional male fertility in maize. Sexual Plant Reproduction 8: 231-241

Pollak PE, Vogt T, Mo Y, Taylor LP (1993) Chalcone synthase and flavonol accumulation in stigmas and anthers of Petunia hybrida. Plant Physiol 102: 925-932

Smyth DR, Bowman JL, Meyerowitz EM (1990) Early flower development in Arabidopsis. Plant Cell 2: 755-767

Tanaka Y, Yonekura K, Fukuchi-Mizutani M, Fukui Y, Fujiwara H, Ashikari T, Kusumi T (1996) Molecular and biochemical characterization of three anthocyanin synthetic enzymes from Gentiana triflora. Plant Cell Physiol 37: 711-716

Taylor LP, Jorgensen R (1992) Conditional male fertility in chalcone synthase-deficient petunia. J Heredity 83: 11-17

Taylor LP, Helper PK (1997) Pollen germination and tube growth Annu. Rev. Plant Physiol. Plant Mol Biol 48: 461-491

Tsuchiya T, Toriyama K, Ejiri S, Hinata K (1994) Molecular characterization of rice genes specifically expressed in the anther tapetum. Plant Mol Biol 26: 1737-1746

Twell D, Yamaguchi J, McCormick S (1990) Pollen-specific gene expression in transgenic plants: coordinate regulation of two different tomato gene promoters during microsporogenesis. Development 109: 705-713

Twell D, Yamaguchi J, Wing RA, Ushiba J, McCormick S (1991) Promoter analysis of genes that are coordinately expressed during pollen development reveals pollen-specific enhancer sequences and shared regulatory elements. Genes Dev 5: 496-507

van der Meer IM, Spelt CE, Mol JNM, Stuitje AR (1990) Promoter analysis of the chalcone synthase (chsA) gene of Petunia hybrida: a $67 \mathrm{bp}$ promoter region directs flower-specific expression. Plant Mol Biol 15: 95-109

van der Meer IM, Stam ME, van Tunen AJ, Mol JN, Stuitje AR (1992) Antisense inhibition of flavonoid biosynthesis in petunia anthers results in male sterility. Plant Cell 4: 253-262

van Eldik GJ, Reijnen WH, Ruiter RK, van Herpen MM, Schrauwen JA, Wullems GJ (1997) Regulation of flavonol biosynthesis during anther and pistil development, and during pollen tube growth in Solanum tuberosum. Plant $J$ 11: $105-113$

van Tunen AJ, Hartman SA, Mur LA, Mol JNM (1989) Regulation of chalcone flavanone isomerase $(\mathrm{CHI})$ gene expression in Petunia hybrida: the use of alternative promoters in corolla, anthers and pollen. Plant Mol Biol 12: 539-551

van Tunen AJ, Mur LA, Brouns GS, Rienstra JD, Koes RE, Mol JN (1990) Pollen- and anther-specific chi promoters from petunia: tandem promoter regulation of the chiA gene. Plant Cell 2: 393-401

van Tunen AJ, Mur LA, Recourt K, Gerats AG, Mol JN (1991) Regulation and manipulation of flavonoid gene expression in anthers of petunia: the molecular basis of the Po mutation. Plant Cell 3: 39-48

Wiermann R, Gubatz S (1992) Pollen wall and sporopollenin. In Russell SD, Dumas C (eds) International Review of Cytology 140. Elsevier, St. Louis, pp 35-72

Winkel BSJ (2006) The biosynthesis of flavonoids. In Grotewold E (ed) The Science of Flavonoids. Springer, New York, pp 71-95

Ylstra B, Touraev A, Moreno RMB, Stoger E, van Tunen AJ, Vicente O, Mol JNM, Heberle-Bors E (1992) Flavonols stimulate development, germination, and tube growth of tobacco pollen. Plant Physiol 100: 902-907

Ylstra B, Busscher J, Franken J, Hollman PCH, Mol JNM, van Tunen AJ (1994) Flavonols and fertilization in Petunia hybrida: localization and mode of action during pollen tube growth. Plant J 6: 201-212

Zerback R, Bokela M, Geigera H, Hess D (1989) A kaempferol 3glucosylgalactoside and further flavonoids from pollen of Petunia hybrida. Phytochemistry 28: 897-899 